$$
\begin{array}{lllllllll}
\text { A } & \text { R } & \text { T } & \text { I } & \text { C } & \text { U } & \text { L } & 0 & \text { S }
\end{array}
$$





\title{
Posicionamiento de las bibliote- cas universitarias peruanas en los medios de comunicación
}

\author{
Alonso Estrada-Cuzcano * \\ Roxana Huaman-Huriarte **
}

Artículo recibido:

4 de mayo de 2010.

Artículo aceptado:

24 de junio de 2010.

\section{RESUMEN}

El propósito de este trabajo es analizar la presencia de las bibliotecas universitarias peruanas en los medios de comunicación del país. Para tal fin se investigaron 37 medios [escritos] (diarios, revistas, agencias de noticias y radios) de cobertura regional y nacional, y se tomaron en consideración las notas o noticias, columnas, artículos, entrevistas y publicidad que hicieran referencia a este tipo de bibliotecas.

La investigación ha demostrado que la presencia de las bibliotecas universitarias en los medios de comunicación es marginal, puesto que en tres años, comprendidos entre enero de 2007 y diciembre de 2009, sólo se pudieron encontrar 43 ocurrencias, a pesar de que

* Universidad Nacional Mayor de San Marcos, Perú. mestradac@unmsm.edu.pe

** Universidad Católica del Perú, Perú. roxana.huaman@pucp.edu.pe

INVESTIGACIÓN BIBLIOTECOLÓGICA, Vol. 24, Núm. 51, mayo/agosto, 2010, México, ISSN: 0187-358X. pp. 13-41 
muchas bibliotecas (o universidades) tienen oficinas de imagen institucional. Estas ocurrencias están distribuidas entre 17 universidades de un total de 98 existentes en el país lo cual demuestra que aún no hay una corriente que fomente el posicionamiento de estas bibliotecas.

Palabras clave: Bibliotecas universitarias; medios de comunicación masivos; Perú; publicidad; posicionamiento; redes sociales; Web 2.0.

\begin{abstract}
Positioning of peruvian university libraries in mass media

Alonso Estrada Cuzcano and Roxana Huaman Huriarte

The purpose of this work is to assess the profile of Peruvian university libraries in mass media. To this end, thirty-seven media outlets, including daily newspapers, magazines, wire services and radio stations providing regional and national coverage were monitored and/or examined. Over a period of three years, straight news stories, columns, feature articles, interviews and advertising referring to university-based libraries were tabulated, showing for the universe of 98 universities in the country a mere 43 mentions, despite the fact that many universities have institutional communications and media offices. These results suggest that currently little effort is being made to enhance or develop the positioning of university libraries.
\end{abstract}

Key words: University libraries; mass media; Peru; social networks; advertising; positioning; Web 2.0.

\title{
INTRODUCCIÓN
}

F n los últimos tiempos se ha podido apreciar el impacto que las nuevas - tecnologías han causado en la sociedad. Se ha visto que las personas ya no se conforman con ser espectadores sino que ahora desean participar, intervenir e interactuar con la realidad que se les presenta.

Las bibliotecas no están excluidas de este fenómeno. Están cambiando su modus operandi, y ahora se orientan hacia lo que se considera el futuro de 
las bibliotecas: la sociedad de la información y, en el afán por subirse a la ola, a veces se descuidan aspectos fundamentales, como por ejemplo la administración y gestión de bibliotecas. Está demostrado que no basta con comprar libros, elaborar alertas bibliográficas o cambiar el mobiliario. Esto no es suficiente, es necesario darse a conocer de forma efectiva.

Desde la biblioteca más pequeña hasta la más grande, todas tienen los servicios y productos básicos para poder desarrollar marketing. Solo basta tener el interés y las ganas de demostrar cuán grande se es y las ventajas que se ofrecen a los usuarios. Los bibliotecarios no pueden cerrar los ojos ante una realidad tan evidente: si quieren sobrevivir en el tiempo y tener la atención que necesitan, deben desarrollar marketing. Asimismo, no pueden simplemente mantenerse al margen de las prácticas de administración, pues, si se medita al respecto, será fácil darse cuenta que las bibliotecas son entidades que bien pueden funcionar como empresa.

Toda empresa de éxito y que logre sobrevivir en el tiempo ha considerado la inserción de principios de administración de empresas, de recursos humanos y económicos. Las bibliotecas no escapan a ello, pues la promoción, la publicidad y el marketing, que son temas ampliamente difundidos en ambientes empresariales o comerciales, en los últimos años también han ganado presencia en el mundo de las bibliotecas y la información.

En la $63^{\circ}$ Conferencia del IFLA realizada en 1997 en Copenhague, Greta Renborg $^{1}$ hizo un recuento del pasado, y sostiene que los bibliotecarios descubrieron formas de promocionar sus bibliotecas mucho antes que dichas actividades se conocieran como marketing propiamente dicho. Los primeros esfuerzos en realzar la imagen de la biblioteca, de promocionar sus servicios, de llegar a sus usuarios mediante medios de comunicación masiva datan de fines del siglo XIX. Estas iniciativas empezaron con sencillas exhibiciones, publicación de guías para los usuarios, conversatorios, entre otros.

Sin embargo, a pesar de que poco a poco los conceptos y definiciones del marketing van conociéndose más entre los profesionales de la información, son muy pocos quienes desarrollan un plan de marketing o insertan ciertas prácticas en sus unidades de información. Como consecuencia, las bibliotecas académicas o universitarias tienen poca presencia institucional o llegan a calar muy poco en el subconsciente de sus usuarios.

Ante este vacío, urge empaparse de los principios de marketing a fin de lograr llegar a todos los usuarios reales y potenciales para, de esta forma, sustentar y justificar el desembolso económico que nuestras bibliotecas demandan.

1 R. Savard (ed.). (2000). Adapting marketing to libraries in a changing and world-wide environment = Le marketing des bibliothèques á l'beure du changement et de la mondialisation. München: K.G. Saur. 
Para comprender un poco más cómo funciona, es necesario desarrollar conceptos teóricos fundamentales: administración, planificación estratégica y marketing propiamente dicho. Estos conceptos serán revisados más adelante.

La investigación tiene como objetivos los siguientes:

- Determinar el posicionamiento que tienen las bibliotecas universitarias peruanas en los medios de comunicación masiva

- Analizar los estilos periodísticos más utilizados por medios de comunicación masiva para reseñar las actividades o servicios realizados por las bibliotecas universitarias peruanas.

- Establecer el posicionamiento de las bibliotecas universitarias peruanas en Internet, evaluando el uso de las herramientas y medios que brinda la Web 2.0.

Esta investigación es de carácter exploratorio cuantitativo y, para desarrollarla, se estudió un total de 37 medios de comunicación. De éstos, 17 son medios de circulación nacional y 20 de carácter regional. Entre los medios estudiados hay una revista, una agencia de noticias nacional, 5 radios y 30 diarios; todos ellos cuentan con un sitio web. Sin embargo, es necesario indicar que 5 diarios se editan exclusivamente en línea.

Se han revisado también medios que utilizan exclusivamente Internet (Web 2.0), como son: Youtube, Facebook, MySpace, Flickr, Twitter y los blogs que contienen información de las bibliotecas; para estos medios se ha realizado un conteo aparte.

Asimismo, el universo de universidades peruanas que se consideró para el estudio es el siguiente: la Asamblea Nacional de Rectores (ANR) tiene bajo su jurisdicción 72 universidades, siendo 28 públicas y 44 privadas, ${ }^{2}$ mientras que la Comisión Nacional de Funcionamiento de Universidades (CONAFU), tiene bajo su jurisdicción a 27 universidades $^{3}$, en proceso de evaluación antes de su autorización definitiva, de las cuales 4 son públicas y 23 privadas, que suman en total 99 universidades en el país.

Mucha información ha sido recolectada día a día u obtenida de diversas fuentes (amigos, listas de interés, blogs, etc.). Se ha recurrido a motores de búsqueda de los propios medios e inevitablemente también a Google y sus

2 Asamblea Nacional de Rectores. (2009). Universidades bajo la jurisdicción de la Asamblea Nacional de Rectores [en línea]. Lima: ANR. Recuperado el 24 de mayo de 2009: http://sigu.anr. edu.pe

3 Asamblea Nacional de Rectores, Consejo Nacional para la Autorización de Funcionamiento de Universidades. (2008). Directorio: universidades bajo la jurisdicción del CONAFU [en línea]. 
herramientas, como por ejemplo Google News; en ambos casos se utilizaron las siguientes estrategias de búsqueda: biblioteca central, biblioteca de la universidad, biblioteca universitaria, bibliotecas universitarias, sistema de bibliotecas, biblioteca y universidad. Se seleccionaron los artículos que incluyeran mínima o parcialmente alguna situación relacionada con las bibliotecas y fueron excluidos los que en su contenido mencionaban la palabra biblioteca pero no desarrollaban ningún punto relacionado con la misma. No se han tomado en consideración las actividades realizadas en bibliotecas como eventos, exposiciones o agendas culturales en general.

Una cuestión que llama la atención en los medios, es la confusión que existe en el uso del término biblioteca virtual en lugar de utilizar términos más adecuados como: centros o laboratorios de cómputo, o catálogos en línea, también llamados OPACs.

Es necesario hacer algunas aclaraciones sobre la metodología: en primer lugar, se incluyó la publicidad - a pesar de no ser un género periodístico - que realizaron las bibliotecas universitarias porque cumplen un rol determinado en la visibilidad de las propias bibliotecas y las universidades. En segundo lugar, no se incluyó en el estudio algunos portales, porque no son específicamente informativos y tampoco se agregaron algunas agencias de noticias en línea porque hacen una re-difusión de noticias que producen otros medios.

Finalmente, si la recuperación de la información no ha sido todo lo exhaustiva posible, se debe a que los motores de búsqueda de los medios estudiados presentan dificultades de recuperación o simplemente los propios medios retiran la información que no es reciente, como el caso de RPP; solo los diarios El Comercio y La República tuvieron resultados eficientes. Otro problema que presentan muchos de los diarios es que la información aparece con la fecha del día en curso y no del día de publicación, lo que en los hechos demuestra que todavía hay un enorme trabajo para lograr una mejora sustancial de la prensa digital.

\section{Marketing: Algunas Definiciones}

Las organizaciones son entidades compuestas de un grupo de personas que se orientan a un determinado fin, y para alcanzarlo, plantean, ejecutan y evalúan una serie de acciones con tal de alcanzar su propósito. ${ }^{4}$ Teniendo en cuenta esto, una organización debe planificar sus acciones a futuro con el fin

4 S.P. Robbins y Coulter, M. (2000). Administración. (6a. ed.). Naucalpan de Juárez: Pearson Educación. 
de crecer, desarrollarse y perdurar en el tiempo, y evitando, en la medida de lo posible, que los cambios de su entorno afecten su desempeño. He aquí lo que se conoce como administración.

La planificación es el proceso que permite proyectarse de forma metódica y organizada hacia objetivos previamente establecidos y se plasma en el plan estratégico, herramienta básica y fundamental de toda organización, que es lo suficientemente estricta para alcanzar las metas y lo suficientemente flexible para acomodarse a los cambios de su entorno. Este documento representa la columna vertebral de la organización, pues expresa la visión, objetivos y estrategias que ha adoptado. Sin embargo, y a pesar del evidente beneficio que aporta a las organizaciones, son pocas, aunque en aumento, las entidades que desarrollan un plan estratégico que les permita proyectarse a futuro. ${ }^{5}$

A pesar de la importancia fundamental que tiene un plan estratégico en las organizaciones, en el ámbito de las bibliotecas universitarias del país solo la Universidad Nacional Mayor de San Marcos ha elaborado este documento guía, que puso en práctica desde el año 2007, con un horizonte temporal de 5 años; además, lo ha puesto a disposición de todos desde su página web. ${ }^{6}$

Pero no solo basta tener un plan estratégico que permita mantenerse en el tiempo. Hace falta también proyectarse hacia quienes se dirigen e idear la mejor forma de llegar al público objetivo, de tal manera que la organización no sea un ente pasivo que espera que sus usuarios lleguen solos sino, por el contrario, uno que busca atraerlos y mostrarles las cualidades y beneficios que tiene para ofrecerles. Esta es la tarea del marketing.

Philip Kotler, ${ }^{7}$ considerado el padre del marketing, lo define como el logro de la satisfacción del cliente, mediante relaciones de intercambio. Para tal fin, el marketing desarrolla una serie de estrategias a fin de llegar a su público objetivo para terminar el proceso en un intercambio que resulte con un usuario satisfecho. Cuando ya se definieron las estrategias que la organización adoptará, es necesario introducir una herramienta fundamental del marketing: el marketing mix. Esta mezcla gira en torno a cuatro variables llamadas las cuatro P's: producto, precio, plaza y promoción; a su vez, cada uno de ellas abarca una serie de actividades.

5 J. Stoner, Freeman, R.E., Gilbert, D.R. (1996). Administración. (6a. ed.). México, D.F.: Prentice-Hall Hispanoamericana.

6 Plan estratégico de la Oficina General del Sistema de Bibliotecas y Biblioteca Central 20072011 (enero de 2007) [en línea]. Lima: Universidad Nacional Mayor de San Marcos, Biblioteca Central Pedro Zulen. Recuperado el 9 de octubre de 2009: http://sisbib-03.unmsm.edu. $\mathrm{pe} / \mathrm{blog} / ? \mathrm{p}=68$

7 P. Kotler, Armstrong, G. (2003). Fundamentos de marketing. (6a. ed.). Naucalpan de Juárez: Pearson Educación. 
Gráfico 1: Las cuatro P's de la mezcla de marketing

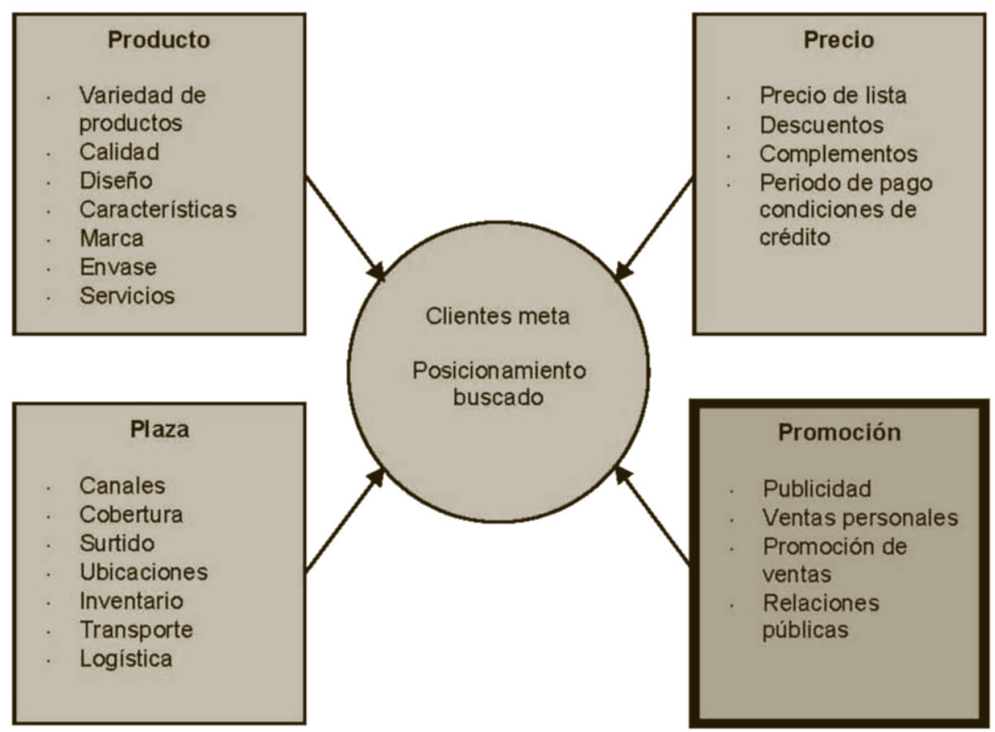

Fuente: Kotler (2003)

Cada una de estas mezclas es importante y tiene una función específica dentro del plan de marketing. Para el caso estudiado, el componente de la mezcla a estudiar será la promoción en bibliotecas.

\subsection{La promoción en el marketing}

El Diccionario de Lengua Española ${ }^{8}$ define la promoción como el conjunto de actividades cuyo objetivo es dar a conocer algo o incrementar sus ventas. En este sentido, la mezcla de promoción del marketing consiste en la combinación de ciertas actividades encaminadas a dar a conocer un producto o servicio usando diferentes formas y medios de comunicación, y resulta importante porque permitirá alcanzar los objetivos iniciales. Es necesario indicar que por más bueno que sea un plan, no será exitoso si es que no se difunde o promociona de la manera adecuada. Así, se debe mostrar y demostrar cómo los servicios o productos que se ofrecen benefician a los usuarios.

Para las bibliotecas es importante ser visibles tratando de evitar un gasto excesivo, pues la gran mayoría carece de un presupuesto destinado a marketing. La promoción de sus servicios en medios de comunicación masivos ya

8 Real Academia Española. (2001). Diccionario de la lengua española. (22a. ed.). Madrid: Espasa Calpe. 
sea prensa escrita, radio, televisión e Internet, es fundamental para, poco a poco, ser visibles ante los ojos de sus usuarios reales y potenciales. El alcance que tengan los medios elegidos, así como la frecuencia de aparición que las bibliotecas guarden, determinará el impacto que producirán en su público objetivo.

Un aspecto clave en la promoción son las relaciones públicas, que tienen como fin influir de forma positiva en la opinión de un determinado sector; además, canalizan los comentarios y sugerencias de su público y definen las estrategias y los medios en que se promocionarán los servicios y productos. Es el lado humano y social de la promoción. Por otro lado, a diferencia de las relaciones públicas, la publicidad se define como una forma impersonal de promocionar a un gran número de personas, y generalmente es pagada. ${ }^{9}$

\section{Bibliotecas universitaRias EN MEdiOS DE COMUNICACIÓN Y GÉNEROS PERIODÍSTICOS}

Los medios de comunicación masiva son aquellos canales que permiten la comunicación entre varias personas, grupos y comunidades. En este sentido, están la prensa escrita, radial o televisiva, y las nuevas tecnologías que han aparecido con el afianzamiento del uso de Internet. Estos medios fomentan y facilitan la socialización entre personas, grupos y sociedades.

A continuación se incluyen definiciones sobre algunos tipos de géneros periodísticos que han sido utilizados en la investigación. Cabe precisar que para muchos autores los géneros no tienen una división o clasificación exacta.

Según Escribano Hernández ${ }^{10}$ la noticia es el texto periodístico cuya función principal es la de relatar hechos nuevos, de interés general y de cierta relevancia pública; puede afirmarse que busca un acontecimiento sorprendente o trascendental y especialmente reciente. También se le llama nota.

El artículo es un

escrito, de muy vario y amplio contenido, de varia y muy diversa forma, en el que se interpreta, valora o explica un hecho o una idea actuales, de especial trascendencia, según la convicción del articulista; ${ }^{11}$

9 J.R. Dominick (2006). La dinámica de la comunicación masiva: los medios de la era digital. (8a. ed.). México, D.F.: McGraw-Hill Interamericana.

10 Asunción Escribano Hernández (2006). Comentario de textos periodísticos: informativos, in terpretativos y de opinión. Salamanca: Ediciones Universidad de Salamanca. 
es decir, la opinión del autor es total y refleja la visión particular del hecho.

Para Gutiérrez Coba ${ }^{12}$

las definiciones se refieren a la entrevista como la reproducción de un diálogo, es una conversación en el cual se intercalan preguntas y respuestas de manera natural, no como un interrogatorio destinado únicamente a la obtención de datos;

se buscan opiniones o precisiones propias de la persona y deben excluirse descripciones interpretativas del entrevistado.

Gargurevich ${ }^{13}$ señala que la columna "es una sección fija, de cierta periodicidad de aparición" y añade que

tiene entonces como otra característica básica el elemento personal; es distinta de la redacción del resto del diario en el sentido de dar mayor énfasis a la opinión personal;

puede ser escrita por un periodista o un especialista (abogado, economista, médico, psicólogo, etc.) que puede dar mayores alcances de una noticia o tema.

Se encontraron en los medios de comunicación y en sus diversos géneros periodísticos referencias a 19 bibliotecas universitarias de un total de 63 referencias (a veces un género menciona a más de una universidad); aunque se debe precisar que solo 3 de las universidades tienen 31 referencias que hacen un aproximado de un 50\% del total de menciones (ver Gráfico 2). Hay 2 menciones a la labor de las bibliotecas en general sin especificar una universidad específica sino que, más bien, se refieren a la problemática de las mismas.

Resulta claro que existe una mejora en relación con los medios de comunicación masiva. En el último año hay una irrupción en los diversos medios de la Universidad Peruana de Ciencias Aplicadas - UPC y se puede notar una política orientada a una amplia difusión de sus logros mostrando su nueva infraestructura y sus nuevos servicios; sin embargo, la Universidad Nacional Mayor de San Marcos - UnMsm y la Pontificia Universidad Católica del Perú - PUCP siguen ligeramente posicionadas en los primeros puestos en el conteo general de los últimos años.

12 L.M. Gutiérrez Coba (2005). La entrevista o el arte de saber preguntar. En César Mauricio Velásquez O., Liliana María Gutiérrez C., Alberto Salcedo R., Jesús Erney Torres L., Jairo Valderrama V. Manual de géneros periodísticos (pp. 59-87). Bogotá: Universidad de La Sabana.

13 Juan Gargurevich R. (2000). Géneros periodísticos. Quito: Ciespal. 
Gráfico 2: Posicionamiento de las bibliotecas en los medios
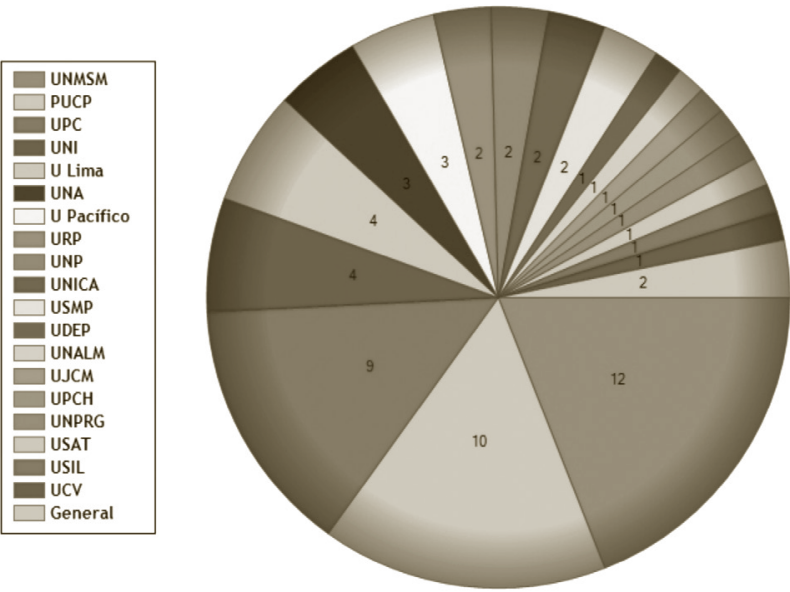

Fuente: Elaboración propia

El total de información encontrada fue de 44 ocurrencias: 10 correspondientes al 2007, 10 correspondientes al 2008 y 24 correspondientes al 2009 (hay una mejora clara en relación con los medios de comunicación masiva). En el último año hay una irrupción en los diversos medios de la Universidad Peruana de Ciencias Aplicadas - UPC y se puede notar una política orientada a una amplia difusión de sus logros mostrando su nueva infraestructura y sus nuevos servicios; sin embargo, la Universidad Nacional Mayor de San Marcos-UNMSM y la Pontificia Universidad Católica del Perú-PUCP siguen ligeramente posicionadas en los primeros puestos en el conteo general de los últimos años.

Los diarios que concentraron mayor información fueron El Comercio con 12 ocurrencias y La República con 9 ocurrencias; ambos diarios constituyeron casi el 50\% del total de ocurrencias, debido a que tienen una amplia cobertura a temas muy diversos, entre ellos los de bibliotecas. Expreso y la revista Caretas tuvieron 4 ocurrencias cada uno, mientras que El Regional de Piura y Correo tuvieron 3 ocurrencias cada uno, este último diario tiene 14 ediciones regionales. La agencia Andina, Perú. 21 y Los Andes tuvieron 2 ocurrencias cada medio. Finalmente, La Primera, RPP y Crónica Viva tuvieron una ocurrencia cada uno (Ver Gráfico 3). 


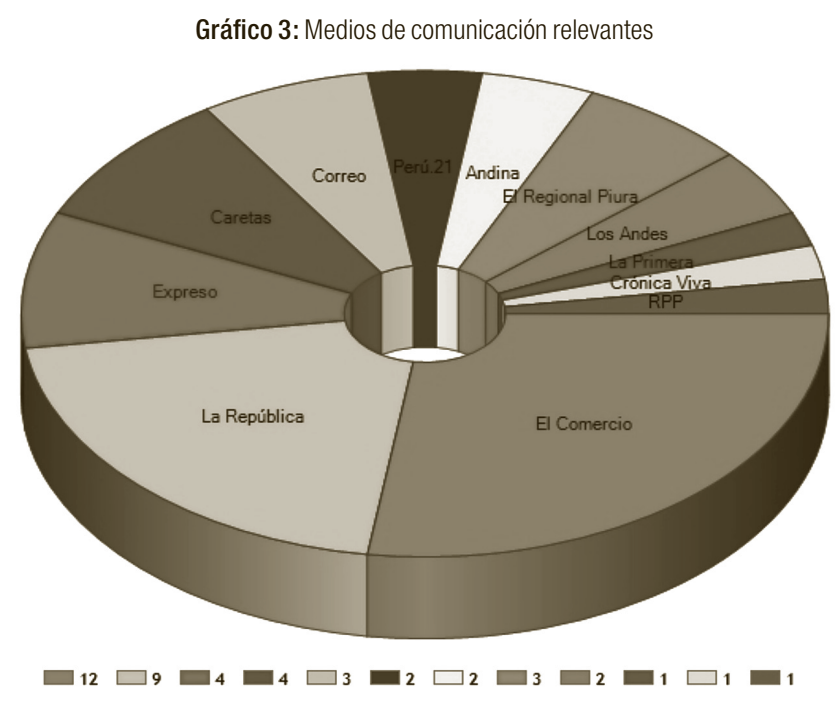

Fuente: Elaboración propia

\subsection{Notas (o noticias) y Articulos}

Las notas o noticias breves suman 18 , lo que da como resultado más de un tercio del total de las ocurrencias encontradas. Las notas cortas tienen información muy puntual que está relacionada con horarios, adquisiciones, servicios o convenios realizados, entre otra. Inclusive hay notas que no exceden dos o tres líneas en los diarios.

Este tipo de información aparece, en su mayoría, como resultado del envío de notas de prensa. Como ejemplo está la Universidad del Pacífico-UP, que relanzó su biblioteca con el concepto de Centro de Recursos para el Aprendizaje, la Investigación y la Docencia; esta información aparece igual en dos medios incluyendo las fotos, pues coinciden en los diarios en los que reseñan la nota. Asimismo, la noticia más corta corresponde a la Universidad César Vallejo con apenas 49 palabras aproximadamente; y la más extensa cubre la inauguración de la nueva biblioteca de la Universidad de Lima.

Por otro lado, los artículos encontrados son 11 y tienen un sinnúmero de áreas temáticas que cubren las bibliotecas universitarias y es uno de los géneros más utilizados en los medios. No se hace una descripción de los artículos porque están dispersos dentro del estudio. 


\subsection{Columnas}

Es preciso indicar que Rocío Silva Santisteban, Abelardo Oquendo y Manuel Burga son columnistas del diario La República. Rocío Santisteban (poeta) tiene una denominada Kolumna Okupa que también se publica en Internet, donde escribe como usuaria e investigadora, y señala las dificultades para el acceso, consulta y préstamo en las diversas bibliotecas universitarias. Vale recordar que Santisteban ${ }^{14}$ es quien escribe una polémica columna dedicada a los Bibliotecólogos que trajo consigo respuestas de todo tipo por parte del gremio bibliotecario.

Abelardo Oquendo (crítico literario) en su columna Inquisiciones, y debido al reciente problema de la venta de libros robados del patrimonio de la Biblioteca Nacional del Perú ${ }^{15}$, recuerda una situación parecida ocurrida en la Biblioteca Central Pedro Zulen de la UNMSM ${ }^{16}$ y opina a manera de denuncia.

El historiador Manuel Burga fue rector de la UNMSM, y escribe habitualmente sobre la problemática universitaria, donde se encuentra también la Biblioteca Central Pedro Zulen. La columna de Burga ${ }^{17}$ hace un análisis de la situación de la citada biblioteca a partir de una tesis de maestría que reseña su historia desde 1923 a $1966 .{ }^{18}$ Anteriormente, Burga ${ }^{19}$ también manifestaba su preocupación por la desaparición de libros en las bibliotecas de San Marcos, pérdida que calculaba en 2 millones de volúmenes.

\subsection{Entrevistas}

Las entrevistas aparecidas en el período estudiado tienen como protagonista indiscutible a Milagros Morgan, bibliotecóloga, directora del Centro de Información de la UPC, quien aparece en los medios para dar a conocer las innovaciones que se producen en la unidad de información que ella dirige. Existe

14 Rocío Silva Santisteban (1 de marzo de 2008). Bibliotecólogos. Domingo la revista de La República [en línea]. Recuperado el 17 de marzo de 2009: http://kolumnaokupa.blogsome. com/2008/03/01/bibliotecologos/

15 Abelardo Oquendo (22 de febrero de 2009). Libros robados. Fama, suplemento de La República, pp.6.

16 Abelardo Oquendo (4 de febrero de 2003). Saqueando la biblioteca de San Marcos. La República, pp. 24.

17 Manuel Burga (11 de diciembre de 2008). Nuestra biblioteca central. La República, pp.15.

18 Antonio Ismael Cajas Rojas (2008). Historia de la Biblioteca Central de la Universidad de San Marcos: 1923 a 1966. Tesis para optar el grado de Magíster en Historia, Facultad de Ciencias Sociales, Universidad Nacional Mayor de San Marcos. Lima, Perú. [En línea]. Recuperado el 12 de mayo de 2009: http://www.cybertesis.edu.pe/sisbib/2008/cajas_ra/pdf/cajas_ra.pdf.

19 Manuel Burga (22 de setiembre de 2004). ¿Bibliotecas saqueadas en San Marcos? La República, pp. 15 . 
la convicción que la función de una directora indiscutiblemente es convocar a los medios y presentar los logros de su gestión, esta presencia también implica un posicionamiento de la propia universidad.

Una entrevista resaltante es la que se realiza en $\operatorname{RPP}^{20}$ y tiene como objetivo mostrar a la opinión pública el oneroso impuesto que pagan las universidades en las compras de bases de datos académicas. Las otras entrevistas tocan parcialmente el tema de las bibliotecas universitarias.

\subsection{Publicidad}

En cuanto a publicidad son pocas las bibliotecas que utilizan este medio para difundir sus servicios. Aquí resalta la publicidad utilizada por dos universidades: la PUCP y la UPC, porque se centran íntegramente en sus bibliotecas.

Se puede decir que la PUCP es pionera en este aspecto, pues en 1998 aparece la siguiente publicidad: Millones de ratones invadirán nuestra gran biblioteca y resalta las posibilidades tecnológicas de un catálogo en línea (Webcat) utilizado vía Internet, ${ }^{21}$ tecnología muy innovadora en ese tiempo. Más adelante, en el 2008 y luego de 10 años de uso de su catálogo en línea, la PUCP promueve una nueva interfaz llamada iLink, el cual es un metabuscador que conjuga los últimos avances tecnológicos para el ámbito de las bibliotecas y por supuesto, felicita a todos los bibliotecarios que hicieron posible la innovación; en este último caso no se recurrió a la publicidad sino que utilizaron su propio blog para recordar tal fecha.

La UPC ${ }^{22}$ presenta la nueva infraestructura de su centro de información y lo enmarca como un nuevo concepto de biblioteca universitaria, enfatizando sus posibilidades tecnológicas a través de recursos digitales y menciona la implementación de un nuevo sistema integrado de biblioteca llamado Aleph. Esta publicidad resulta la más sustancial porque se publicó hasta tres veces, 2 veces en el 2008 y 1 el 2009, y cumple con los principios propios de la publicidad: llamar la atención y generar interés.

La revista Caretas tiene una Sección Publicitaria Especial dedicada a las universidades y se encontraron tres publirreportajes que se reseñan a continuación. Dos de los espacios publicitarios tocan el tema de las bibliotecas parcialmente; el primero, es dedicado a los 90 años de la PUCP y en ese marco presenta, en primera instancia, los servicios, sus 9 bibliotecas, 2 hemerotecas,

20 León Trahtemberg y Salcedo, José María. Ampliación de noticias [Entrevista a Ruth Chirinos y Alonso Estrada Cuzcano]. Lima: RPP.

21 "Millones de ratones invadirán nuestra gran biblioteca". (15 de febrero de 1998). El Comercio, pp. C-1.

22 Centro de Información de la UPC: el espacio de conocimiento más moderno del Perú. (2008). Somos, 21(1110), 17. 
6 centros de documentación y su medio millón de libros y revistas. El segundo publirreportaje pertenece a la Universidad San Martín de Porres y presenta a sus facultades. Lo trascendente aquí es que la Facultad de Derecho muestra a su biblioteca especializada como su mejor fortaleza. El tercer espacio publicitario, en dos páginas con amplias fotos, promueve los servicios de la nueva biblioteca de la Universidad de Lima y resalta el intensivo uso de tecnología como $W i$-Fi, autoservicio, multimedia, entre otros. Esta irrupción en la publicidad por parte de esta universidad resulta muy importante porque muestra a la biblioteca como el eje de la enseñanza universitaria.

En el Gráfico 4, se muestra el universo de géneros periodísticos encontrados y que hacen referencia en sus contenidos a bibliotecas universitarias peruanas.

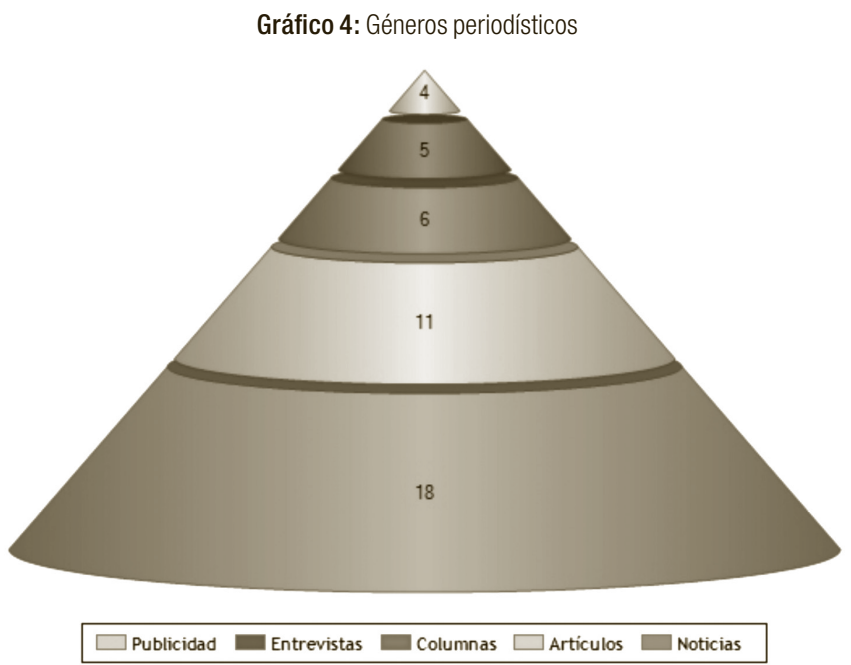

Fuente: Elaboración propia

\section{Espacios temáticos PREPONDERANTES EN LOS MEdios}

Es difícil establecer espacios temáticos preponderantes porque hay una mezcla de tópicos o asuntos de importancia. Por ejemplo, se puede notar en los géneros investigados temas como: infraestructura, servicios, gestión o tecnología, tocados indistintamente en los géneros investigados.

Los servicios de información se promueven continuamente a través de los medios pues existen 10 ocurrencias, y van de la mano con los soportes tecnológicos tal como lo hacen la UPC, Universidad de Lima y Universidad del Pacífico. 
Las adquisiciones y colecciones interesan a los medios porque aún se mantiene el concepto de excelencia académica a través de bibliotecas actualizadas. Se informa de las adquisiciones que se hacen en universidades de provincias gracias al canon minero; pero también se realizan denuncias relacionadas con las compras de material bibliográfico sobrevaluado.

Como un asunto latente en las bibliotecas universitarias se presentan las compras de las bases de datos comerciales, cuyo problema en la adquisición radica en el impuesto del 30\% que se les aplica; el texto legislativo (inciso i, art. $9^{\circ}$ del Decreto Supremo $N^{\circ} 179-2004-E F$ sustituido por art. $4^{\circ}$ del Decreto Legislativo $\mathrm{N}^{\circ} 970$ publicado el 24.12.2006 y vigente desde 1.1.2007) dice:

Las obtenidas por servicios digitales prestados a través del Internet o de cualquier adaptación o aplicación de los protocolos, plataformas o de la tecnología utilizada por Internet o cualquier otra red a través de la que se presten servicios equivalentes, cuando el servicio se utilice económicamente, use o consuma en el país.

Este problema aparece como tema central en una entrevista realizada a integrantes del Consorcio Altamira ${ }^{23}$, y en un artículo y una noticia se indica que el impuesto es un impedimento para el desarrollo digital de las bibliotecas universitarias se señala que el Estado les impone un 30\% a todos los servicios en línea que no sean producidos en el Perú ${ }^{24}$ y se añade que la norma buscaba aplicar impuestos a los software, pero incluyeron a todos dentro de un mismo saco. ${ }^{25}$

También la infraestructura tiene un gran impacto debido a la modernización, remodelación o la inauguración de nuevas bibliotecas. Una gran cobertura tiene la nueva biblioteca de la Universidad de Lima, de un total de 6 pisos que incluyen sótano y terraza, 3 pisos de $1.000 \mathrm{~m} 2$ cada uno están destinados para las colecciones especializadas; la biblioteca esta totalmente automatizada y con un uso intensivo de tecnología como: identificación por radiofrecuencia — RFID_ para la marcación única de libros, Wi-Fi y buzones automáticos de devolución.

Asimismo, hay modernizaciones y construcciones de nuevas bibliotecas que tuvieron poco impacto en los medios. La UNI inició la construcción de una nueva biblioteca central en un área total de 5,000 $\mathrm{m}^{2}$ aproximadamente y una inversión de 10 millones de soles; antes de iniciar la construcción se convocó a un

23 León Trahtemberg y Salcedo, José María., op. cit.

24 Sergio Rebaza (2009). Revolución editorial: copyright, los e-books en la encrucijada de los derechos de autor. Somos, 22(1185), 52-54.

25 Cruzada digital: continúa lucha por exonerar de impuestos a libros y revistas digitales. (2009). Caretas (2098), 73. 
concurso arquitectónico ganado por el Arq. José Antonio Quiroz Farías, ${ }^{26}$ y salvo una nota, este acontecimiento no tuvo mayor repercusión a pesar de su importancia.

La Universidad del Pacífico reinauguró su biblioteca y muestra cambios en infraestructura y servicios: sistema de estantería abierta, formación de usuarios, conexión $W i$-Fi, biblioteca virtual y ambientes totalmente remodelados. Un desastre natural como el terremoto de Pisco tampoco se elude y se recogen notas sobre la destrucción de las bibliotecas universitarias existentes en la Universidad San Luis Gonzaga de Ica.

$\mathrm{La}$ atención sobre el patrimonio documental surge en parte a causa de la devolución de los libros a la Biblioteca Nacional del Perú (BNP) que fueron saqueados en la Guerra con Chile de 1879. Este hecho motiva que universidades históricas como la UNMSM y la UNI (ex Escuela de Ingenieros) aparezcan en los medios y se retome un antiguo reclamo del patrimonio expoliado de ambas instituciones académicas durante la guerra de $1879 .{ }^{27}$ El ex director de la BNP, Sinesio López, insiste en esta devolución en dos entrevistas hechas para el diario Perú.21. ${ }^{28}{ }^{29}$ Loza $^{30}$ describe el catálogo de la Biblioteca de San Marcos en ese entonces: "ese catálogo, ordenado alfabéticamente por autor tiene tres categorías sistemáticas: autor, título y número de 'tomos'. Una parte significativa de los títulos y los nombres está incompleta o equivocada. El catálogo incluye en total 5,076 'tomos'... Quizá no podríamos esperar más, dado lo incipiente de las ciencias bibliotecarias", a pesar de los datos inexactos estos deberían tomarse en cuenta por la Comisión del Ministerio de Relaciones Exteriores encargada de la devolución de este patrimonio.

La Biblioteca Central de la UNMSM muestra algunas de sus joyas bibliográficas redescubiertas, en este caso es un manuscrito de Francisco de Paula González Vigil que se presumía desaparecido. ${ }^{31}$ Cuesta, ${ }^{32}$ investigador de Vigil dice: "de sus 31 escritos hemos podido recuperar 26. Creemos que otras 3 de sus obras pueden haberse perdido porque apenas se dispone de información de ellas", allí radica la importancia del manuscrito presuntamente desaparecido por mucho tiempo.

26 Concurso arquitectónico biblioteca UNI. (5 de julio de 2007) [en línea]. [Lima]: Amarengo. Recuperado el 3 de julio de 2009: http://amarengo.gorg/node/347

27 Enrique Sánchez Hernani (10 de mayo de 2009). Los libros secuestrados. El Dominical, suplemento de El Comercio, pp. 6-7.

28 Entrevista.21 [Entrevista a Sinesio López]. (18 de marzo de 2007). Peru21, pp.8-9.

29 Gonzalo Pajares Cruzado (7 de noviembre de 2007). No han devuelto todos los libros que se llevaron [Entrevista a Sinesio López]. Perú21, pp. 21.

30 Alberto Loza Nehmad (2008). La biblioteca que San Marcos perdió con la Guerra: ¿Cuál biblioteca, cuáles libros? Universidad Mayor, 1(3), 14-15.

31 Revoredo, Alberto. (25 de marzo de 2007). Un histórico manuscrito. El Comercio, pp. C-22.

32 Marcelino R. Cuesta (2002). Las relaciones Estado-Iglesia en el Perú republicano: la polémica Vigil-Gual. Anuario de Historia de la Iglesia, 11, 435-443. 
Paradójicamente temas que se reclaman de actualidad constante como la tecnología, no tienen mucho impacto o no se difunden en los medios. Es muy limitada la información relativa a la tecnología; aunque se debe precisar que complementariamente a la presentación de los servicios e infraestructura bibliotecarios siempre hay menciones a la tecnología pero no es el tema central.

Uno de los artículos más importantes en este rubro es el de CybertesisUNMSM, que incorpora videos a las tesis digitales existentes; de esta forma los propios autores hacen una descripción de su trabajo de investigación ${ }^{33}$ en el video. Otro artículo significativo es el de Agustín ${ }^{34}$ que resalta la importancia de la utilización de los formatos digitales y la posibilidad de alternar con espacios físicos o virtuales a través de la utilización de la Web 2.0; describe experiencias de la UPC y Cibertec en el uso de metabuscadores, servicios de bibliotecario en línea, entre otros. La experiencia en el uso de meta-buscadores en las bibliotecas de la UPC y la PUCP muestra que estas herramientas tecnológicas facilitan al investigador la recuperación de la información de forma rápida, exhaustiva y pertinente. ${ }^{35}$

\section{Bibliotecas universitarias Peruanas EN LA Web 2.0}

Es O'Reilly ${ }^{36}$ quien señala los elementos constitutivos de lo que se denomina Web 2.0, especialmente establece características relacionadas con la gestión y producción de contenidos. Nafría ${ }^{37}$ afirma que es la revolución de los servicios en Internet, de tal forma que el usuario ya no es más solo espectador, si no que se convierte en el protagonista porque no solo elige contenidos, sino que los crea, y fomenta el uso y desarrollo de las aplicaciones que se encuentran en Internet. Esta dinámica ha dado paso al boom de las redes sociales que promueven la formación de comunidades; contenidos haciendo uso de herramientas que favorecen la escritura en línea: blogs, wikis, fotografías, videos, diapositivas, agendas; organización social de la información, gracias a las herramientas y recursos necesarios para etiquetar, redistribuir e indizar, que facilitan la organización del conocimiento: motores de búsqueda, RSS,

33 Sandro Medina (9 de mayo de 2008). Fomentan la difusión de tesis digitalizadas con el video: Se accederá a web con más de 1.500 tesis de 5 centros universitarios: plataforma en línea es impulsada por la Universidad de San Marcos. El Comercio, pp. A-12.

34 Wilson A. Agustín (2009). Del libro al tecno: fuente de poder: Internet transformando el acceso a la información. Somos, 22(1178), 48-52.

35 Investigación en la red. (6 de agosto de 2009). Maestrías suplemento de El Comercio, pp. 12 14.

36 Tim O'Reilly (2007). What is web 2.0: design patterns and business models for the next generation of software. Social Science Research Network Working Paper Series, 1(65), 17-37.

37 I. Nafría (2008). Web 2.0: el usuario, el nuevo rey de Internet. Barcelona: Gestión 2000. 
marcadores sociales; y aplicaciones y servicios (herramientas, software, plataformas en línea, etc.). A su vez, esta revolución da lugar a nuevas formas de comunicación y de acceso a información, como se aprecia en el Gráfico 5.

A pesar que los blogs aparecieron en el transcurso del año 1997, recién en el 2004, de acuerdo a Google Trends, empieza su ascenso y masificación. Los blogs, o conocidos también como bitácoras, son creados para difundir aquello que su autor piense u opine sobre determinado asunto sin necesidad de trabajar para una empresa de noticias. Además de escribir periódicamente, esta herramienta permite recibir comentarios de aquellos que los leen. Por otro lado, las redes sociales, o también llamadas comunidades virtuales en Internet que permiten asociar personas según intereses o perfiles, irrumpieron con mayor fuerza en el año 2003, y a la fecha las más representativas son Facebook, Hi5, MySpace, Twitter, entre otros.

Gráfico 5: Web 2.0

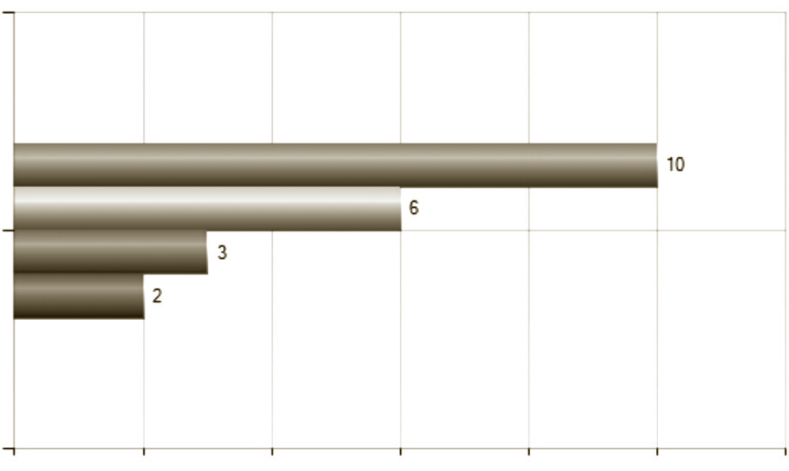

Fuente: Elaboración propia

En el estudio se encontraron 10 videos, 6 blogs, mientras que 3 bibliotecas que utilizan las redes sociales, y 2 bibliotecas han implementado visitas, tours o guías virtuales. P. Sólo hay 2 bibliotecas que tienen dominio propio para sus blogs: la Pontificia Universidad Católica del Perú, que desde el 2007 tiene 58 post, y algunos de estos alcanzaron hasta 22,000 visitas; y la Universidad Nacional Mayor de San Marcos, que desde el 2008 tiene 15 post y no se actualiza constantemente.

Hay 4 bibliotecas que no utilizan dominios propios en sus blogs: la Biblioteca Central de la UNI, que desde el 2008 tiene 60 post; la Biblioteca Central de la USAT, con 40 post desde el 2009 destinados a difundir noticias de la propia biblioteca; la Biblioteca Central de la UDEP (campus de Piura y Lima) sólo hace una difusión de sus adquisiciones hemerográficas a través de dos blogs diferentes, ambos creados el 2009: Piura tiene 74 posts y Lima 123 
posts, lo cual resulta una sub-utilización de esta herramienta; y la última es la Biblioteca de la Facultad de Ingeniería Geográfica, Ambiental y Ecoturismo de la UNFV que utiliza el blog como un tablón de anuncios y tiene 14 posts desde el 2009.

La UNMSM, la UNI y la PUCP están usando la red social Facebook, las dos primeras universidades de forma no oficial y la última oficialmente. En la UNMSM la red social no tiene fines estrictamente académicos y se supone que no es oficial pues los usuarios envían mensajes diversos, pero es oportuno comentar la impresionante popularidad que tiene, casi llega a los 5,000 seguidores. La Biblioteca Central de la UNI usa también Picasa y Flickr, herramientas web para compartir imágenes, la iniciativa de los bibliotecarios de esta universidad resulta loable porque utilizan los recursos gratuitos de la red con una mínima inversión y cuyo principal capital es la motivación. La PUCP es la biblioteca de más reciente incursión en el Facebook y señala explícitamente que es oficial así como el Twitter, bajo el usuario "Bibliopucp".

Otro exponente del fenómeno de la Web 2.0 es sin lugar a dudas Youtube. Esta herramienta permite ver y compartir videos a todo el mundo, con el agregado de recibir valoraciones y comentarios de los usuarios. Ariew ${ }^{38}$ afirma que los videos en Internet son usados cada vez más como fuente primaria o complemento para clases académicas. Y siendo este el escenario, las bibliotecas y los bibliotecarios pueden aprovechar este recurso para difundir y promocionar sus colecciones y servicios. Como ejemplo Ariew ${ }^{39}$ presenta a las bibliotecas de The University of California, San Diego, quienes tuvieron un impacto positivo en sus usuarios con respecto a sus videos de promoción de los servicios. A pesar del gran uso de Youtube y del amplio contenido temático que se puede encontrar, muy pocas son las bibliotecas del país que se han animado a usarla, inclusive hay pocos videos oficiales centrados en las bibliotecas universitarias.

Universia TV ha comenzado a crear espacios para los videos pero hasta ahora sólo se han producido 2 relacionados con las bibliotecas universitarias. Además, se encontraron 8 videos institucionales referidos a la biblioteca universitaria: 4 videos institucionales muestran un panorama general de las bibliotecas; 1 video sobre la inauguración de una colección especializada y 3 sobre los recursos informativos de la biblioteca.

El primero, encontrado en Universia TV, contiene información sobre la adecuación de la biblioteca de la Universidad del Pacífico hacia un nuevo concepto de Centro de Recursos para el Aprendizaje, Investigación y

38 S. Ariew (2008). YouTube culture and the academic library: a guide to online open access educational videos. Choice, 45(12), 2057-2063.

39 S Ariew, op cit. 
Docencia ${ }^{40}$. El segundo video recoge información sobre la inauguración de la nueva biblioteca de la Universidad de Lima y sus nuevos servicios apoyados en un amplio soporte tecnológico ${ }^{41}$.

La PUCP tiene dos videos institucionales: el primero sobre la Biblioteca Central (versión 2005) y un segundo sobre el servicio de referencia, aunque al parecer fueron producidos antes del 2007 y luego se incorporaron a la web en ese año, por tal motivo se consideran en este estudio; el problema de estos videos es la poca visibilidad pues solo aparecen en su sitio web y deberían difundirse por otros medios. La UNMSM tiene dos videos institucionales elaborados TV San Marcos: el primero resalta la importancia de la Biblioteca Central, aunque esta aparición se reduce a segundos; ${ }^{42}$ un segundo video muestra exclusivamente a la Biblioteca de la Facultad de Medicina de San Marcos conocida también como San Fernando. Se encontró un vídeo institucional elaborado por la Universidad Peruana Unión (UpeU) y se pueden notar dos aspectos importantes: la estantería abierta y el uso de bases de datos para obtener información académica. ${ }^{43}$

La Universidad de Piura - $\mathrm{UDEP}^{44}$ — muestra la inauguración de una sala y colección especializada dedicada a José María Desantes Guanter, estudioso y pionero del derecho a la información en Hispanoamérica; los créditos de este vídeo son institucionales (Canal UdePiura).

La Biblioteca Central de la Universidad de Lima muestra un video sobre el uso de la biblioteca y sus recursos informativos, y de igual forma la Universidad ESAN muestra sus servicios mediante un video institucional. ${ }^{45}$

Finalmente, las bibliotecas de la PUCP y la UPC muestran en sus respectivas web, tours o guías virtuales por las instalaciones de sus bibliotecas, lo que puede considerarse como promoción externa de estas bibliotecas, puesto que al estar en Internet, no solo es visto por su comunidad sino por el resto del mundo.

40 Fiorella Meza y Gambetta, Alberto. (20 de enero de 2009). CRAID: moderna biblioteca U. del Pacifico [Entrevista con Eva Flores]. [Video en línea]. [Lima]: Universia. Recuperado el 28 de mayo de 2009: http://vimeo.com/2898354?pg=embed\&sec

41 Alberto Gambetta, Alberto (16 de febrero de 2009). Nueva biblioteca de la Universidad de Lima [video en línea]. [Lima]: Universia. Recuperado el 28 de mayo de 2009: http://vimeo. com/3236568

42 Teledusm. (21 de mayo de 2008). Promo TV San Marcos [video en línea]. Lima: UnMSM. Recuperado el 11 de junio de 2009: http://www.youtube.com/watch?v=4FTZEL-xauI

43 G. Bazualdo, Carmen Ross y Oblitas B., Sheridan. (5 de julio de 2009). UPeU Biblioteca [video en línea]. Lima: Universidad Peruana Unión. Recuperado el 8 de julio: http://www.youtube. $\mathrm{com} /$ watch? $\mathrm{v}=\mathrm{KTMSUYhqiK} 8$

44 Universidad de Piura. (2007). Universidad de Piura - inauguración Bibloteca Desantes [video en línea]. Piura: UDEP. Recuperado el 2 de julio de 2009: http://www.youtube.com/ watch? $\mathrm{v}=\mathrm{vXoCBMCZk} 1 \mathrm{Y}$

45 ESAN. (2009). Biblioteca y Centro de Información Esan/Cendoc [video en línea]. Lima: Universidad ESAN. Recuperado el 13 de diciembre: http://esancendoc.esan.edu.pe/index. php?option=com_content $\&$ view $=$ article $\& i d=43 \&$ Itemid $=62$. 


\section{Conclusiones}

1. La presencia de las bibliotecas universitarias en los medios de comunicación es marginal. En tres años de estudio solo se encontraron 44 ocurrencias a pesar de que muchas bibliotecas o universidades tienen oficinas de imagen institucional. La proporción de bibliotecas universitarias que aparecen en los medios en relación del total también es mínima. La presencia en los medios debe ser un indicador exigible y válido para determinar el posicionamiento de una biblioteca y de la propia universidad.

2. La gran mayoría de bibliotecas universitarias no inciden en desarrollar publicidad en el marco de un proyecto de marketing. Las apariciones de las bibliotecas universitarias en los medios de comunicación analizados no responden a un plan de publicidad y promoción elaborado, si no más bien a una coyuntura favorable.

3. Existen estrategias de marketing que pueden mejorar la presencia de las bibliotecas dentro de las universidades. Como primer paso es necesaria la utilización de la prensa interna ${ }^{46}$, un segundo paso es mirar hacia los medios de comunicación masivos. Esta nueva actitud también se verá reflejada en las universidades y por supuesto captarán la atención de los lectores para con el trabajo del profesional bibliotecario.

4. Algunas bibliotecas peruanas están incorporando nuevos usos de tecnologías como los blogs, las redes sociales y los videos en Internet. A pesar de promoverse nuevas herramientas de comunicación, existen distancias enormes entre el discurso frecuente y la práctica real. Las bibliotecas universitarias no tienen otra elección porque los servicios y las informaciones que brinden a los usuarios deberán ser preeminentemente virtuales.

5. No pueden pasar desapercibidos en nuevos trabajos de investigación los medios que se desarrollan en Internet porque con éstos surgen nuevos contenidos, nuevos estilos periodísticos y modos de presentación de los productos informativos, como por ejemplo hipermedia y multimedia. Las características principales de este nuevo periodismo son la inmediatez, la amplitud e interactividad y deberían tomarse en cuenta en estudios posteriores. Por ejemplo, es imprescindible estudiar las webs y blogs peruanos que tienen carácter informativo y

46 Biblioteca 2.0 (2009, junio). Neo [en línea]. Vol. 1, no. 6. Recuperado el 21 de julio de 2009: http://www.pucp.edu.pe/puntoedu/dmdocuments/num146.pdf 
producen sus propias noticias y videos ocupando un espacio diferente al de los medios tradicionales (La Mula, El Morsa, Útero de Marita, etc.).

\section{REFERENCIAS BIBLIOGRÁFICAS}

Agustín, Wilson A. (2009). Del libro al tecno: fuente de poder: Internet transformando el acceso a la información. Somos, 22(1178), $48-52$.

Ariew, S. (2008). YouTube culture and the academic library: a guide to online open access educational videos. Choice, 45(12), 20572063.

Asamblea Nacional de Rectores. (2009). Universidades bajo la jurisdicción de la Asamblea Nacional de Rectores [en línea]. Lima: ANR. Recuperado el 24 de mayo de 2009: http://sigu.anr.edu.pe

Asamblea Nacional de Rectores, Consejo Nacional para la Autorización de Funcionamiento de Universidades. (2008). Directorio: universidades bajo la jurisdicción del CONAFU [en línea]. Recuperado el 24 de mayo de 2009: http://www.anr.edu.pe/conafu/univer. html

Bazualdo G., Carmen Ross y Oblitas B., Sheridan. (5 de julio de 2009). UPeU Biblioteca [video en línea]. Lima: Universidad Peruana Unión. Recuperado el 8 de julio: http://www.youtube.com/ watch? $v=$ KTMSUYhqiK8

Biblioteca 2.0 (2009, junio). Neo [en línea]. Vol. 1, no. 6. Recuperado el 21 de julio de 2009: http://www.pucp.edu.pe/puntoedu/dmdocuments/num146.pdf

Burga Manuel. (22 de setiembre de 2004). ¿Bibliotecas saqueadas en San Marcos? La República, pp.15.

Burga Manuel. (11 de diciembre de 2008). Nuestra biblioteca central. La República, pp.15.

Cajas Rojas, Antonio Ismael. (2008). Historia de la Biblioteca Central de la Universidad de San Marcos: 1923 a 1966. Tesis para optar el grado de Magíster en Historia, Facultad de Ciencias Sociales, Universidad Nacional Mayor de San Marcos. Lima, Perú. [En línea]. Recuperado el 12 de mayo de 2009: http://www.cybertesis. edu.pe/sisbib/2008/cajas_ra/pdf/cajas_ra.pdf.

Centro de Información de la UPC: el espacio de conocimiento más moderno del Perú. (2008). Somos, 21(1110), 17.

Concurso arquitectónico biblioteca UNI. (5 de julio de 2007) [en línea]. [Lima]: Amarengo. Recuperado el 3 de julio de 2009: http://amarengo.gorg/node/347

Cruzada digital: continúa lucha por exonerar de impuestos a libros y revistas digitales. (2009). Caretas (2098), 73. 
Cuesta, Marcelino R. (2002). Las relaciones Estado-Iglesia en el Perú republicano: la polémica Vigil-Gual. Anuario de Historia de la Iglesia, 11, 435-443.

Dominick, J.R. (2006). La dinámica de la comunicación masiva: los medios de la era digital. (8a. ed.). México, D.F.: McGraw-Hill Interamericana.

Entrevista.21 [Entrevista a Sinesio López]. (18 de marzo de 2007). Peru21, pp.8-9.

ESAN. (2009). Biblioteca y Centro de Información Esan/Cendoc [video en línea]. Lima: Universidad ESAN. Recuperado el 13 de diciembre: http://esancendoc.esan.edu.pe/index.php?option=com_con tent $\&$ view $=$ article $\&$ id $=43 \&$ Itemid $=62$

Escribano Hernández, Asunción. (2006). Comentario de textos periodisticos: informativos, interpretativos y de opinión. Salamanca: Ediciones Universidad de Salamanca.

Gambetta, Alberto. (16 de febrero de 2009). Nueva biblioteca de la Universidad de Lima [video en línea]. [Lima]: Universia. Recuperado el 28 de mayo de 2009: http://vimeo.com/3236568 .

Gargurevich R., Juan. (2000). Géneros periodísticos. Quito: Ciespal.

Gutiérrez Coba, L.M. (2005). La entrevista o el arte de saber preguntar. En César Mauricio Velásquez O., Liliana María Gutiérrez C., Alberto Salcedo R., Jesús Erney Torres L., Jairo Valderrama V. Manual de géneros periodísticos (pp. 59-87). Bogotá: Universidad de La Sabana.

Inauguración Biblioteca Fac. Medicina UNT [video en línea] (6 de enero de 2009). [Trujillo]: [s.n.]. Recuperado el 9 de octubre de 2009: http://www.youtube.com/watch?v=WkrGK_P4GX8

Investigación en la red. (6 de agosto de 2009). Maestrías suplemento de El Comercio, pp. 12-14.

Kotler, P., Armstrong, G. (2003). Fundamentos de marketing. (6a. ed.). Naucalpan de Juárez: Pearson Educación.

Loza Nehmad, Alberto. (2008). La biblioteca que San Marcos perdió con la Guerra: ¿Cuál biblioteca, cuáles libros? Universidad Mayor, 1(3), 14-15.

Martín Vivaldi, Gonzalo. (1973). Géneros periodísticos: reportaje, crónica, artículo: análisis diferencial. Madrid: Paraninfo.

Medina, Sandro. (9 de mayo de 2008). Fomentan la difusión de tesis digitalizadas con el video: Se accederá a web con más de 1.500 tesis de 5 centros universitarios: plataforma en línea es impulsada por la Universidad de San Marcos. El Comercio, pp. A-12.

Meza, Fiorella y Gambetta, Alberto. (20 de enero de 2009). CRAID: moderna biblioteca U. del Pacifico [Entrevista con Eva Flores]. [Video en línea]. [Lima]: Universia. Recuperado el 28 de mayo de 2009: http://vimeo.com/2898354?pg=embed\&sec

Millones de ratones invadirán nuestra gran biblioteca. (15 de febrero de 1998). El Comercio, pp. C-1. 
Nafría, I. (2008). Web 2.0: el usuario, el nuevo rey de Internet. Barcelona: Gestión 2000.

O'Reilly, Tim. (2007). What is web 2.0: design patterns and business models for the next generation of software. Social Science Research Network Working Paper Series, 1(65), 17-37.

Oquendo, Abelardo. (4 de febrero de 2003). Saqueando la biblioteca de San Marcos. La República, pp. 24.

Oquendo, Abelardo. (22 de febrero de 2009). Libros robados. Fama, suplemento de La República, pp. 6.

Pajares Cruzado, Gonzalo. (7 de noviembre de 2007). No han devuelto todos los libros que se llevaron [Entrevista a Sinesio López]. Perú21, pp. 21.

Plan estratégico de la Oficina General del Sistema de Bibliotecas y Biblioteca Central 2007-2011 (enero de 2007) [en línea]. Lima: Universidad Nacional Mayor de San Marcos, Biblioteca Central Pedro Zulen. Recuperado el 9 de octubre de 2009: http://sisbib-03. unmsm.edu.pe/blog/?p=68

Real Academia Española. (2001). Diccionario de la lengua española. (22a. ed.). Madrid: Espasa Calpe.

Rebaza, Sergio. (2009). Revolución editorial: copyright, los e-books en la encrucijada de los derechos de autor. Somos, 22(1185), 52-54.

Revoredo, Alberto. (25 de marzo de 2007). Un histórico manuscrito. ElComercio, pp. C-22.

Robbins, S.P. y Coulter, M. (2000). Administración. (6a. ed.). Naucalpan de Juárez: Pearson Educación.

Sánchez Hernani, Enrique. (10 de mayo de 2009). Los libros secuestrados. El Dominical, suplemento de El Comercio, pp. 6-7.

Savard, R., (ed.). (2000). Adapting marketing to libraries in a changing and world-wide environment $=$ Le marketing des bibliothèques á l'beure du changement et de la mondialisation. München: K.G. Saur.

Silva Santisteban, Rocío. (1 de marzo de 2008). Bibliotecólogos. Domingo la revista de La República [en línea]. Recuperado el 17 de marzo de 2009: http://kolumnaokupa.blogsome. com/2008/03/01/bibliotecologos/

Stoner, J., Freeman, R.E., y Gilbert, D.R. (1996). Administración. (6a. ed.). México, D.F.: Prentice-Hall Hispanoamericana.

Teledusm. (21 de mayo de 2008). Promo TV San Marcos [video en línea]. Lima: UNMSM. Recuperado el 11 de junio de 2009: http:// www.youtube.com/watch?v=4FTZEL-xauI

Trahtemberg, León y Salcedo, José María. Ampliación de noticias [Entrevista a Ruth Chirinos y Alonso Estrada Cuzcano]. Lima: RPP.

Universidad de Piura. (2007). Universidad de Piura - inauguración Bibloteca Desantes [video en línea]. Piura: UDEP. Recuperado el 2 de julio de 2009: http://www.youtube.com/watch?v=vXoCBMCZk1Y 


\section{ANEXO 1}

Medios de comunicación investigados

\section{Diarios, revistas y radios de alcance nacional}

1. Andina - Agencia Peruana de Noticias

2. Caretas

3. Coordinadora Nacional de Radios

4. Correo (14 ediciones regionales)

5. CPN Radio

6. Diario La Primera

7. El Comercio

8. El Peruano

9. Expreso

10. Kapital

11. La Republica

12. $0 \mathrm{jo}$

13. Perú.com (online)

14. Perú21

15. Pro\&Contra (Iquitos)

16. Radio Nacional

17. Radio Programas del Perú

\section{Diarios regionales}

1. Crónica Viva: pasión por la noticia (Ancash) (online)

2. Diario Chasqui - en línea (Apurimac)

3. Diario de Chimbote

4. Diario del Cusco

5. Diario el Sol del Cusco

6. Diario Integración (Ancash)

7. Diario Jornada (Ayacucho)

8. Diario La Voz de Huamanga

9. Diario Noticias (Arequipa)

10. Diario Regional de Piura (online)

11. Diario Ya (Ancash)

12. El Ferrol Periodico (Ancash)

13. El Pueblo (Arequipa)

14. El Tiempo de Piura

15. Hoy (Huanuco)

16. La Industria (La Libertad)

17. La Industria de Chimbote

18. Los Andes (Puno)

19. Panorama de Cajamarca

20. Periodismo en línea 


\section{ANEXO 2 \\ Artículos, columnas, noticias o publicidad recogidos de los medios de comunicación}

1. A la vanguardia del desafío académico: completamente renovada, la Universidad de Lima inauguró ayer, con la asistencia de personalidades, su nueva biblioteca. Cuenta con cinco pisos y cuatro niveles especializados para sus alumnos y docentes (13 de febrero de 2009). El Comercio, pp. A-9

2. A seguir leyendo puneño (19 de febrero de 2009) [en línea]. Los Andes. Recuperado el 10 de julio de 2009: http://www.losandes.com.pe/Cultural/20090219/19132.html.

3. Abrirán acceso a biblioteca de la UNI (25 de enero de 2009). Expreso.

4. Agustín, Wilson A. (2008). Enchufe permanente: el profesional de la información frente a los vertiginosos cambios que impone la tecnología. Somos, (1105), 64-68.

5. Agustín, Wilson A. (2009). Del libro al tecno: fuente de poder: Internet transformando el acceso a la información. Somos, 22(1178), 48-52.

6. Biblioteca automatizada: Universidad de Lima, primera en el país con tecnología total para la autonomía y la investigación (2009). Caretas, (2097), 88-89.

7. Burga Manuel. (11 de diciembre de 2008). Nuestra biblioteca central. La República, pp.15.

8. Camacho, Ángel (30 de abril de 2009). Biblioteca de la UNICA: al servicio de la población. Correo.

9. Centro de Información de la UPC: el espacio de conocimiento más moderno del Perú. (2008). Somos, 21(1110), 17.

10. Centro de Información de la UPC: el espacio de conocimiento más moderno del Perú. (2008). Somos, 21(1112), 17.

11. Centro de Información de la UPC: el espacio de conocimiento más moderno del Perú. (2008). Somos, 22(1158), 19.

12. Con la más alta tecnología al servicio del hombre: Universidad San Martín de Porres (2007). Caretas, (1998), 84-85.

13. Consorcio de Universidades Nacionales acuerda mejorar calidad académica: se reunieron en Piura (18 de enero de 2009). Diario Regional de Piura [en línea]. Recuperado el 18 de abril de 2009: http://www.elregionalpiura.com.pe/archivonoticias_2009/enero_2009/ enero_18/regionales_18j.htm

14. Construyen nueva biblioteca en la UNI: mejora en el campus (4 de octubre de 2008). EI Comercio, pp. A-12.

15. CRAID, nuevo modelo bibliotecario (14 de enero de 2009). Expreso, pp. 14.

16. CRAID: nuevo concepto en la UP (9 de enero de 2009). La República, pp. 25.

17. Cruzada digital: continúa lucha por exonerar de impuestos a libros y revistas digitales. (2009). Caretas (2098), 73.

18. Desde hace 5 años la UNA - Puno compra libros cada mes (14 de abril de 2007) [en línea]. Los Andes. Recuperado el 24 de junio de 2009: http://www.losandes.com.pe/Sociedad/20070414/6113.html.

19. Entrevista.21 [Entrevista a Sinesio López]. (18 de marzo de 2007). Peru21, pp.8-9.

20. Espejo, Karen (11 de mayo de 2008). Libros de bibliotecas iqueñas se amontonan en sacos [Entrevista a Alonso Estrada Cuzcano]. La República, pp. 28.

21. Graham., Raúl (2 de febrero de 2009). Tesoros bibliográficos. Crónica Viva [en línea]. Recuperado el 18 de abril de 2009: http://www.cronicaviva.com.pe/content/view/72192/353/

22. Inician construcción de nueva Biblioteca Central de la UNI: una demandará inversión de S/. 10 millones (3 de octubre de 2008). Andina: Agencia Peruana de Noticias [en línea]. Recuperado el 19 de abril de 2009: http://www.andina.com.pe/Espanol/Noticia. aspx?id= JexlhJXTews

23. Investigación en la red (6 de agosto de 2009). Maestrías suplemento de El Comercio, pp. 12-14. 
24. Instituto de Cultura de Italia dona libros a gobierno regional y municipios (21 de octubre de 2008). Andina: Agencia Peruana de Noticias [en línea]. Recuperado el 20 de abril de 2009: http://www.andina.com.pe/espanol/Noticia.aspx?id=tCc+uqfyXn0

25. Medina, Sandro (9 de mayo de 2008). Fomentan la difusión de tesis digitalizadas con el video: Se accederá a web con más de 1.500 tesis de 5 centros universitarios: plataforma en línea es impulsada por la Universidad de San Marcos. El Comercio, pp. A-12.

26. Nueve décadas después: la Pontificia Universidad Católica en la actualidad (2007). Sección publicitaria especial. Educación: Nuevos rumbos, retos y oportunidades de un mercado más exigente. Caretas, (1977), 6-7.

27. Oquendo, Abelardo. (22 de febrero de 2009). Libros robados. Fama, suplemento de La República, pp.6.

28. Pacheco, Alberto (11 de febrero de 2009). Nueva torre: mañana se inaugura la remodelada biblioteca de la Universidad de Lima. El Comercio, pp. A-16.

29. Pajares Cruzado, Gonzalo. (7 de noviembre de 2007). No han devuelto todos los libros que se llevaron [Entrevista a Sinesio López]. Perú21, pp. 21.

30. Ramos, Alonso (6 de octubre de 2008). Región Moquegua compra libros a precios altos en licitación. La Repúblic, pp. 7.

31. Rebaza, Sergio. (2009). Revolución editorial: copyright, los e-books en la encrucijada de los derechos de autor. Somos, 22(1185), 52-54.

32. Realizan coordinaciones finales para la biblioteca virtual (5 de julio de 2009). Correo.

33. Revoredo, Alberto. (25 de marzo de 2007). Un histórico manuscrito. El Comercio, pp. C-22.

34. Reyes, Rousell (16 de mayo de 2009). Bibliotecas e internet [Entrevista a Milagros Morgan]. Expreso, pp. B-14.

35. Sánchez Hernani, Enrique. (10 de mayo de 2009). Los libros secuestrados. El Dominical, suplemento de El Comercio, pp. 6-7.

36. Silva Santisteban, Rocío (14 de mayo de 2007). El saber-mercancía. Domingo la revista de La República, pp. 7.

37. Silva Santisteban, Rocío ( 5 de febrero de 2007). La instrucción gratuita en mi vida. Domingo la revista de La República, pp. 23.

38. Silva Santisteban, Rocío (6 de mayo de 2007). ¿Qué leen los que no leen? Domingo la revista de La República, pp. 6.

39. Trahtemberg, León y Salcedo, José María. Ampliación de noticias [Entrevista a Ruth Chirinos y Alonso Estrada Cuzcano]. Lima: RPP.

40. UCV adquiere mil 400 libros: para biblioteca (21 de junio 2009). Correo.

41. Universidad Nacional de Piura recibe importante donación de libros para biblioteca (7 de enero de 2009). Diario Regional de Piura [en línea]. Recuperado el 18 de abril de 2009: http://www.elregionalpiura.com.pe/archivonoticias_2009/enero_2009/enero_07/ regionales_07h.htm

42. Universidad Nacional de San Agustín recibió S/. 20 millones por concepto de canon minero: dinero será invertido en compra de equipos de laboratorio y libros para 47 facultades (1 de enero de 2009). Andina: Agencia Peruana de Noticias [en línea]. Recuperado el 18 de abril de 2009: http://www.andina.com.pe/Espanol/Noticia.aspx?ld=qgmF/nS/JqQ

43. Universidad, modernidad y ciberlibros [Entrevista a Milagros Morgan] (11 de mayo de 2009). La Primera, pp. 17.

44. Universidades firman acuerdos (8 de agosto de 2008). El Comercio, pp. B-6.

45. Valdivia Paz-Soldán, Rosario (1 de julio de 2009). Sistema de bibliotecas de la URP. Expreso, pp. 10.

46. Vizcarra, Julissa (3 de julio de 2009). Bibliotecas hoy: ofrecen diferentes formas de obtener y procesar la información. Correo, pp. 15. 
WEB 2.0

47. Alerta hemerográfica Universidad de Piura Biblioteca Central Campus Piura (2009) [en línea]. Recuperado el 16 de julio de 2009: http://alertahemerograficaudep-piura.blogspot.com/

48. Alerta hemerográfica Universidad de Piura Biblioteca Central Campus Lima (2009) [en línea]. Recuperado el 28 de setiembre de 2009: http://alertahemerograficaudep-lima.blogspot.com

49. Bazualdo G., Carmen Ross y Oblitas B., Sheridan. (5 de julio de 2009). UPeU Biblioteca [video en línea]. Lima: Universidad Peruana Unión. Recuperado el 8 de julio: http://www. youtube.com/watch?v=KTMSUYhqiK8

50. Biblioteca de la Facultad de Ingeniería Geográfica, Ambiental y Ecoturismo de la UNFV (2009) [en línea]. Recuperado el 23 de septiembre de 2009: http://bibliotecafigaeunfv. blogspot.com

51. Biblioteca (ULIMA) - Recursos comunicativos (2009) [video en línea]. Lima: Universidad de Lima. Recuperado el 28 de noviembre de 2009: http://www.youtube.com/ watch? $\mathrm{v}=\mathrm{qRMcm} 4$ UslkA

52. ESAN. (2009). Biblioteca y Centro de Información Esan/Cendoc [video en línea]. Lima: Universidad ESAN. Recuperado el 13 de diciembre: http://esancendoc.esan.edu.pe/index. php?option $=$ com_content\&view $=$ article\&id $=43 \& \mid$ temid $=62$

53. Blog de la Biblioteca (2007) [en línea]. Lima: Pontificia Universidad Católica del Perú. Recuperado el 13 de junio de 2009: http://blog.pucp.edu.pe/index.php?blogid=1032

54. Gambetta, Alberto. (16 de febrero de 2009). Nueva biblioteca de la Universidad de Lima [video en línea]. [Lima]: Universia. Recuperado el 28 de mayo de 2009: http://vimeo. com/3236568.

55. Meza, Fiorella y Gambetta, Alberto. (20 de enero de 2009). CRAID: moderna biblioteca U. del Pacífico [Entrevista con Eva Flores]. [Video en línea]. [Lima]: Universia. Recuperado el 28 de mayo de 2009: http://vimeo.com/2898354?pg=embed\&sec

56. Noticias biblioteca USAT (2009) [en línea]. [Chiclayo]: Universidad Católica Santo Toribio de Mogrovejo. Recuperado el 31 de julio de 2009: http://bibliotecausat.blogspot.com

57. Pontificia Universidad Católica del Perú. Manual de ayuda y servicios (2007) [en línea]. Lima: Pontificia Universidad Católica del Perú. Recuperado el 28 de mayo de 2009: http://caliope. pucp.edu.pe/MAS

58. Sistema de Bibliotecas de la UNMSM (2008) [en línea]. Lima: Universidad Nacional Mayor de San Marcos. Recuperado el 13 de junio: http://sisbib-03.unmsm.edu.pe/blog

59. Tamayo, Augusto (director) (26 de marzo de 2007). Biblioteca y sala de referencia de la PUCP [video en línea]. Lima: Pontificia Universidad Católica del Perú. Recuperado el 28 de noviembre de 2009: http://videos.pucp.edu.pe/videos/ver/36958c7b919311166b399bfe25de345d

60. Tamayo, Augusto (director) (29 de marzo de 2007). Biblioteca de la PUCP [video en línea]. Lima: Pontificia Universidad Católica del Perú. Recuperado el 28 de noviembre de 2009: http://videos.pucp.edu.pe/videos/ver/36958c7b919311166b399bfe25de345d

61. Teledusm. (21 de mayo de 2008). Promo TV San Marcos [video en línea]. Lima: UNMSM. Recuperado el 11 de junio de 2009: http://www.youtube.com/watch?v=4FTZEL-xaul

62. TV San Marcos (30 de setiembre de 2009). Biblioteca de la Fac. Medicina "San Fernando" [video en línea]. Lima: TV San Marcos. Recuperado el 30 de setiembre de 2009: http:// www.tvsanmarcos.com/?p=696

63. Universidad de Piura. (2007). Universidad de Piura - inauguración Bibloteca Desantes [video en línea]. Piura: UDEP. Recuperado el 2 de julio de 2009: http://www.youtube.com/ watch? $\mathrm{v}=\mathrm{VX}$ OCBMCZk1Y

64. Universidad Nacional de Ingeniería. Biblioteca Central (2008) [en línea]. Lima: Universidad Nacional de Ingeniería. Recuperado el 3 de julio de 2009: http://bibliotecacentraluni.blogspot.com 
65. Universidad Peruana de Ciencias Aplicadas (2008?). Tour virtual [en línea]. Lima: UPC. Recuperado el 28 de mayo de 2009: http://www.upc.edu.pe/0/modulos/JER/JER_Interna. aspx?ARE $=0 \& \mathrm{PFL}=4 \& \mathrm{JER}=4620$

\section{ANEXO 3 \\ Siglas}

$\begin{array}{ll}\text { ANR } & \text { Asamblea Nacional de Rectores } \\ \text { CONAFU } & \text { Consejo Nacional para la Autorización de Funcionamiento de Universidades } \\ \text { PUCP } & \text { Pontificia Universidad Católica del Perú } \\ \text { RPP } & \text { Radio Programas del Perú } \\ \text { UCV } & \text { Universidad César Vallejo } \\ \text { UDEP } & \text { Universidad de Piura } \\ \text { UEsan } & \text { Universidad Escuela Superior de Administración de Negocios } \\ \text { ULima } & \text { Universidad de Lima } \\ \text { UNA } & \text { Universidad Nacional del Altiplano } \\ \text { UNALM } & \text { Universidad Nacional Agraria de La Molina } \\ \text { UNFV } & \text { Universidad Nacional Federico Villarreal } \\ \text { UNI } & \text { Universidad Nacional de Ingeniería } \\ \text { UNICA } & \text { Universidad Nacional San Luis Gonzaga de Ica } \\ \text { UNJCM } & \text { Universidad José Carlos Mariátegui de Moquegua } \\ \text { UNMSM } & \text { Universidad Nacional Mayor de San Marcos } \\ \text { UNP } & \text { Universidad Nacional de Piura } \\ \text { UNPRG } & \text { Universidad Nacional Pedro Ruiz Gallo } \\ \text { UP } & \text { Universidad del Pacífico } \\ \text { UPC } & \text { Universidad Peruana de Ciencias Aplicadas } \\ \text { UPCH } & \text { Universidad Peruana Cayetano Heredia } \\ \text { UPeU } & \text { Universidad Peruana La Unión } \\ \text { URP } & \text { Universidad Ricardo Palma } \\ \text { USAT } & \text { Pontificia Universidad Santo Toribio de Mogrovejo } \\ \text { USIL } & \text { Universidad San Ignacio de Loyola } \\ \text { USMP } & \text { Universidad San Martín de Porres } \\ & \end{array}$


